\title{
Trauma burden in Tanzania: a one-day survey of all district and regional public hospitals
}

\author{
Hendry R. Sawe ${ }^{1,2^{*}}$, Juma A. Mfinanga ${ }^{1,2}$, Khalid R. Mbaya ${ }^{3}$, Phillip M. Koka ${ }^{1}$, Said S. Kilindimo ${ }^{1,2}$,
} Michael S. Runyon ${ }^{1,4}$, Victor G. Mwafongo ${ }^{1,2}$, Lee A. Wallis ${ }^{5}$ and Teri A. Reynolds $s^{1,6}$

\begin{abstract}
Background: Trauma contributes significantly to the burden of disease and mortality throughout the world, but particularly in developing countries. In Tanzania, there is an enormous research gap on trauma; the limited data available reflects realities in cities and areas with moderately- to highly-resourced treatment centers. Our aim was to provide a description of the injury epidemiology across all of Tanzania. Our data will serve as a basis for future larger studies.

Methods: This is a subgroup analysis of a cross-sectional, prospective study of the clinical epidemiology of patients presenting at all public district and regional hospitals in Tanzania. The study was conducted between May 2012 and December 2012. A team of emergency doctors used a purpose-designed data collection sheet to gather the demographic and clinical information of all patients presenting during the day-site visit to each hospital. Descriptive statistics, including means, standard deviations, medians, and ranges are reported.
\end{abstract}

Results: A total of 5227 patients were seen in 24-h period in 105 (100\% response rate) district (or designated district) and regional hospitals in mainland Tanzania. Of these patients, 508 (9.7\%) presented with trauma-related complaints. Among patients with trauma-related complaints, 286 (56.3\%) were male, and the overall median age of 30 (interquartile range of 22-35) years. Road traffic crash was the most common mechanism of injury, accounting for 227 (44.7\%) complaints. Open wounds and bone fractures were the two most frequent diagnoses, with a combined 300 (59\%) cases. Most of the patients - 325 (64\%) - were discharged, 11 (2.2\%) went to operating theatres and $4(0.8 \%)$ of patients died while receiving care at the acute intake areas.

Conclusions: Trauma-related complaints constitute a substantial burden among patients seeking care in acute intake areas of hospitals across Tanzania. There is a need to develop, implement and study systems that can support the improvement of trauma care and optimize outcomes of trauma patients.

Keywords: Trauma burden, Injured patients, Road traffic crash, Emergency care

\section{Background}

Trauma contributes significantly to the burden of disease and mortality throughout the world, but particularly in developing countries [1-4]. Trauma remains a leading cause of death and disability particularly in paediatric and adolescent populations worldwide. Despite the fact that the quality of the data available from most

\footnotetext{
* Correspondence: hsawe@muhas.ac.tz

'Department of Emergency Medicine, Muhimbili University of Health and

Allied Sciences, P.O. Box 65001, Dar es Salaam, Tanzania

${ }^{2}$ Department of Emergency Medicine, Muhimbili National Hospital, Dar es

Salaam, Tanzania

Full list of author information is available at the end of the article
}

developing countries is relatively poor, the majority of the past efforts at quantifying the global burden of disease $[1,5,6]$ have convincingly established that trauma contributes approximately $10 \%$ to global mortality, and $12 \%$ to global morbidity. Currently, injuries through Road traffic crash (RTC) are ranked ninth globally among the leading causes of disability adjusted life years lost [7]. It is estimated that 1.2 million people are killed in RTCs each year and as many as $\mathbf{5 0}$ million are injured globally [8]. Increasing motorization in many developing countries has seen deaths due to RTCs surge to the 
degree that such injuries are projected to become the third most important health problem by $2020[9,10]$.

In Africa, injuries rank among the top ten mortality causes, and claim more lives than tuberculosis, malaria and HIV combined [11]. In addition, for every death, there are thousands of non-fatal injuries which, though likely under-reported, result in serious impairment that might be preventable with timely treatment $[1,12]$. According to the 2008 WHO injury prevention report, most of the injury burden in the world rests in lowincome and middle-income countries, and within these countries, the poor are disproportionately affected [12, 13]. Africa has the highest rate of road traffic injuries resulting in mortality (28.3 per 100,000 population) when corrected for under-reporting, compared with 11.0 per 100,000 in Europe [14].

Tanzania is a low income-country with a population of 55 million people, of whom $80 \%$ lives in rural area. The life expectancy is approximately 65 years, and HIV is the leading cause of mortality [15]. There is neither formal pre-hospital system, no trauma care system [16]. Most of the patients receive health care through public system, which is provided through a pyramidal structure from dispensary, health centre, district hospital, regional hospital and consultant hospitals [17]. Tanzania is no exception to that trend, with a high burden of injuries across all age groups, and a notable proportion in children [18]. Being a developing country, Tanzania is also expected to experience the increased trauma, particularly due to the RTC epidemic driven by rapid urbanization, poor infrastructure and the epidemic of motorcycle used as transport. Injuries and death from RTCs are expected to increase if no preventive measures are taken [1]. Many of these injuries are preventable, but targeted prevention efforts are hampered by the limited data [19-22], which has traditionally focused on the cities and areas with moderately- to highlyresourced centers in the country leaving a gap in understanding the nature of injury and care in the remainder of the country, particularly rural areas. This poses a unique challenge in understanding the real epidemiology of trauma in Tanzania, given majority of Tanzanians live in rural areas [23]. In this study, we sought to provide a pilot description of the injury epidemiology across all of Tanzania by undertaking a 24-h period cross-sectional prospective audit of all public district and regional hospitals in Tanzania. We believe this data will serve as a basis for future larger studies aiming at secondary prevention of trauma-related illness across Tanzania and broader SubSaharan Africa.

\section{Methods}

\section{Study design}

This is a subgroup analysis of a larger cross-sectional, prospective study, which described the clinical presentation, investigations, procedures and diagnoses of patients presenting to public district and regional hospitals in Tanzania. The larger cross-sectional, prospective study enrolled a consecutive convenience sample of all patients presenting during the randomly selected daylong clinical shift to each hospital. This study was part of Tanzania Emergency Care Capacity Site Survey (TECCSS) project, which aimed at evaluating three main components of emergency care: the disaster preparedness, equipment availability and disease burden in all district and regional hospitals. The TECCSS project was conducted between May 2012 and December 2012.

\section{Study setting}

All district and regional hospitals in Tanzania mainland were included in this audit. Mainland Tanzania (excluding the island of Zanzibar) at the time of this study had 25 regional and 80 district (or designated district) hospitals. The regional hospitals are expected to receive referral of patients from district hospitals and hence offer an expanded range of care and more specialty services than district facilities.

\section{Study protocol}

The data collection was overseen by one of the five authors (PM, HS, JM, KM and SK), who are all emergency physicians. The researchers were randomly divided into different geographical and political areas of Tanzania based on locations of regional and district hospitals. A purpose-designed data collection sheet was used and the data collectors asked treating providers to complete deidentified data sheets on all patients who presented within that period with the assistance of the researcher. Information gathered included basic demographics, clinical presentations, investigations done (example: imaging and laboratory work), procedures done, clinical management including medications, and disposition. Data not gathered as the patient moved through the facility were collected later the same day from patients' medical records.

\section{Data analysis}

The study data were transferred from the hand-written data forms into an Excel database (Microsoft corporation, Redmond, WA) and analyzed with SAS (version 9.3, SAS Institute Inc., Cary, NC, USA). Procedure, frequency and univariate functions of SAS were performed to check for any outliers and clean the dataset. Descriptive statistics, including means, standard deviations, medians, and ranges were calculated.

\section{Ethics approval}

The study protocol was reviewed and approved by the Institutional Review Board of the Muhimbili University 
of Health and Allied Sciences (MUHAS) and Ministry of Health issued a permission to survey all of the hospitals.

\section{Results}

\section{Hospitals surveyed}

We surveyed all 105 district and regional hospitals across mainland Tanzania, and had a $100 \%$ response rate. Of these hospitals, 80 (76.2\%) were district (or designated district) hospitals, and 25 (23.8\%) regional hospitals. The hospitals have been divided in geo-political zones to cover the whole country: There are 14, 10, 10, 19, 10, 6, and 11, district (or designated district) hospitals in the Lake, Eastern, Western, Northern, Southern, Central and Southern Highland zones respectively. Each of 25 political regions had one hospital, and those zones had 3,6, 3, 4, 3, 2, and 4, regional hospitals respectively. Only 11 (10.5\%) hospitals had a dedicated 24-h acute intake area with a dedicated doctor on duty to tend to emergencies.

\section{Patients demographics}

A total of 5227 patients were seen in all hospitals. Of these, $508(9.7 \%)$ patients presented with trauma-related complaints. Most 286 (56.3\%) of these patients were male, and the overall median age among all patients was 30 years (interquartile range 22 to 35 years). The Eastern zone 151 (29.7\%) and southern Western zone 44 (8.7\%) had the highest and lowest number of patients per zones respectively (Table 1).

Table 1 Patients' demographics

\begin{tabular}{lll}
\hline Demographics & $\begin{array}{l}\text { Number } \\
(N=508)\end{array}$ & $\begin{array}{l}\text { Percentage } \\
(\%)\end{array}$ \\
\hline Sex & 286 & 56.3 \\
$\quad$ Male & 222 & 43.7 \\
$\quad$ Female & & \\
Age Group & 24 & 4.7 \\
$\quad<5$ Years & 95 & 18.7 \\
5-15 years & 333 & 65.6 \\
16-55 years & 56 & 11.0 \\
$>55$ years & & \\
Patients by Region ${ }^{a}$ & 151 & 29.7 \\
Eastern Zone & 68 & 13.4 \\
Northern Zone & 96 & 18.9 \\
Lake zone & 50 & 9.8 \\
Southern Zone & 50 & 9.8 \\
Central Zone & 49 & 9.6 \\
Southern Highlands zone & 44 & 8.7 \\
Western Zone & &
\end{tabular}

${ }^{a}$ The number of patients per 100,000 populations is $2.0,1.1,1.5,1.3,1.5,1.0$ and 0.7 for eastern, northern, lake, southern, central, southern highlands and western zone respectively

\section{Mechanism of injury}

RTC 227 (44.7\%) represented the most common mechanism of injury, while poisoning and drowning represented the least common mechanisms (Table 2).

\section{Distribution of injury mechanism by age group}

The overall distribution of injury mechanisms was significantly different across the age groups $(p<0.001)$. Burns and falls were the most common mechanisms among patients under 5 years and 5-15 years of age, respectively, while RTCs were most common among those in the groups of patients $16-55$ years and above 55 years of age (Table 3).

\section{Top diagnosis}

Open wounds and bone fractures were the top two most frequent diagnoses, accounting for $59 \%$ of the top ten diagnoses, while snake-bite $4(0.8 \%)$ was the least frequent diagnosis (Table 4).

\section{Patient disposition}

Most of the patients 325 (64\%) were discharged, 11 (2.2\%) of patients were channelled straight towards the operating theatres, and $0.8 \%$ of patients died while receiving care at the acute intake areas (Table 5).

\section{Discussion}

Our study represents one of the most comprehensive assessments of one-day trauma burden presenting to acute intake areas in districts and regional public hospitals of Tanzania. Most of the previous studies [19, 20, 24] had focused on the cities and areas with moderately- to highly-resourced hospitals, which left a gap in understanding the nature of injury and care in areas with different socio-economic settings. This study involved those areas but also many places not previously studied providing much-needed foundational knowledge of Tanzania's trauma burden.

Trauma-related complaints accounted for about 10\% of the overall complaints of patients presenting to acute intake areas of the health facilities in Tanzania. Middle aged males were the most affected group in our study population, consistent with previously published

Table 2 Mechanism of injury

\begin{tabular}{lll}
\hline Mechanism & $\mathrm{N}=508$ & $\%(95 \mathrm{Cl})$ \\
\hline RTC & 227 & $44.7(40.4-49.0)$ \\
Fall & 98 & $19.3(15.9-22.7)$ \\
Assault & 94 & $18.5(15.1-21.9)$ \\
Animal bite & 55 & $10.8(8.1-13.5)$ \\
Burn & 18 & $3.5(1.9-5.1)$ \\
Others $^{\text {a }}$ & 16 & $3.1(1.6-4.6)$ \\
\hline
\end{tabular}

Poisoning, drowning, foreign body ingestion 
Table 3 Distribution of injury mechanism by age group*

\begin{tabular}{lllll}
\hline AGE GROUP: Year & $<5$ & $5-15$ & $16-55$ & $>55$ \\
\hline $\mathrm{n}$ & 24 & 95 & 333 & 56 \\
RTC (\%) & $6(25.0)$ & $22(23.2)$ & $179(53.8)$ & $20(35.7)$ \\
Fall (\%) & $4(16.7)$ & $35(36.8)$ & $42(12.6)$ & $17(30.4)$ \\
Assault (\%) & $1(4.2)$ & $17(17.9)$ & $72(21.6)$ & $4(7.1)$ \\
Burn (\%) & $8(33.3)$ & $4(4.2)$ & $6(1.8)$ & 0 \\
Animal bite (\%) & $5(20.8$ & $13(13.7)$ & $31(9.3)$ & $6(10.7)$ \\
Others $^{\text {a }}(\%)$ & 0 & $4(4.2)$ & $3(0.9)$ & $9(16.1)$ \\
\hline
\end{tabular}

${ }^{*} p<0.001$ for the overall distribution of injury mechanisms by age group

${ }^{\text {a }}$ Poisoning, drowning, foreign body, other penetrating and other blunt injuries

literature in Tanzania and Sub-Saharan Africa [22, 2527]. Open wounds of the head, limbs, neck or trunk and bone fractures accounted for over $50 \%$ of the diagnoses recorded, highlighting the challenge of caring for patients especially in hospitals situated in regions and districts further away from the single fully equipped trauma care hospital in the country [28]. While trauma from RTCs was the most common mechanism of injury in all the patients, of interest was the finding that more than $10 \%$ of patients presented with injuries from animal bites, in particular dog and cats. This finding highlights an often-unrecognized mechanism that has not been well documented in the past studies, which have primarily focused on RTCs. The significant role of animal bites found in this study is a major issue in Tanzania and most of the developing world due to the fact that few domestic animals have been vaccinated [29]. Animal bites in these areas pose a high risk for transmission of rabies.

The trauma distribution patterns within different age groups differ from those observed in developed countries [30,31], with most patients below the age of five in our study presenting with injuries related to burns. We believe the same socioeconomic factors observed in previous studies in Tanzania contributed to the observed high proportion of children with burns [20, 32]. The

Table 4 Top diagnosis

\begin{tabular}{lll}
\hline DIAGNOSIS & $N=508$ & $\%(95 \mathrm{Cl})$ \\
\hline Open wounds of head, limbs, neck or trunk & 183 & $36.0(31.8-40.2)$ \\
Bone fracture & 117 & $23.0(19.3-26.7)$ \\
Head injury & 49 & $9.6(7.0-12.2)$ \\
Superficial Contusion & 41 & $8.1(5.7-10.5)$ \\
Dog/cat bite & 39 & $7.7(5.4-10.0)$ \\
Polytrauma & 28 & $5.5(3.5-7.5)$ \\
Other Injuries & 23 & $4.5(2.7-6.3)$ \\
Burn & 18 & $3.5(1.9-5.1)$ \\
Visceral injury & 6 & $1.2(0.3-2.2)$ \\
Snake bite & 4 & $0.8(0.03-1.6)$ \\
\hline
\end{tabular}

Table 5 Patients' disposition

\begin{tabular}{lll}
\hline DISPOSITION & $\mathrm{N}=508$ & $\%(95 \mathrm{Cl})$ \\
\hline Discharged & 325 & $64.0(59.8-68.2)$ \\
Admitted & 139 & $27.4(23.5-31.3)$ \\
Referred & 21 & $4.1(2.4-5.8)$ \\
Theatre & 11 & $2.2(0.9-3.5)$ \\
Unknown & 8 & $1.6(0.5-2.7)$ \\
Died & 4 & $0.8(0.03-1.6)$ \\
\hline
\end{tabular}

pattern of RTC-related injuries by age was consistent with studies from both high- and low-income countries [33-36]. Overall, 30\% of all patients were either admitted, referred to higher levels of care or went to theatre. While this study was not designed to comment on the injury severity of the trauma patients, these results suggest a high level of complexity or severity of injuries as well as a possible lack of resources at these sites. The overall mortality in the acute intake areas was less than one-percent. We believe that our study likely under represents the true mortality from trauma given that we did not follow these patients beyond the acute intake area care.

Beyond the huge and diverse trauma burden, another major finding of our study was that only $10 \%$ of hospitals had a dedicated 24-h acute intake area with a dedicated doctor on duty to provide care for patients presenting with emergencies. This is a substantial gap in access to care for patients with trauma-related emergencies that may cause a delay in appropriate treatment. While our study was not designed to identify the reasons for this lack of dedicated 24-h acute intake areas, the observed gap might be a result of combination of resourcerelated factors and the infancy of emergency medicine as a dedicated discipline in Tanzania [16]. Prior studies in Tanzania have documented global lack of emergency equipment and supplies in most of the acute care intake areas of various levels of hospitals [17].

Over half of the trauma-related complaints were reported in the hospitals of the Eastern and Western zones of Tanzania. These zones have regions with both the highest populations and fastest-growing economies, including rapid urbanization and motorization [23]. While these zones accounted for the highest burden in our studies, the trauma care systems in most of these places are still under developed. There is only one full-capacity trauma care centre in Tanzania [28], that is located in the Eastern zone, which had the highest proportion trauma compared to other zones. All patients needing advanced trauma and neurosurgical interventions are dependent on this fully equipped trauma centre. Most patients in lower levels of care (district and regional hospitals) are dependent on clinical officers and assistant medical officers [17]. Since these personnel are not 
trained to provide advanced trauma and neurosurgical interventions, most of such patients will require referral to higher levels of care, most often to the only fully equipped trauma centre in Tanzania.

This study provides a description of a one-day trauma burden among patients seeking emergent care in hospitals across Tanzania. As expected, there is a high burden of trauma in both rural and urban areas. While we have provided pilot data to help guide policy and resource allocation, the study has highlighted areas of further research. We propose that the priorities should be given to supporting the implementation of 24-h emergency care units in all districts and regional hospitals so as to support the provision of life saving resuscitation to trauma patients. Furthermore, future research should focus on implementing a standardized trauma documentation system across the country, to further characterize the risk factors, clinical care, referral patterns and outcomes in order to identify areas of improvement and optimize outcomes.

\section{Limitations}

This was a one-day study that was collected on different days and by different health care professionals. In addition, our results reflect reported and recorded patient characteristics, which may be incomplete. We did, however, include all district and regional hospitals, and gather data in real time during on site visits to each facility, which we believe increases the accuracy of this cross-sectional characterization.

\section{Conclusion}

Trauma-related complaints constitute a substantial burden among patients seeking care in acute intake areas of hospitals across Tanzanian. There is a need to develop, implement and study systems that can support the improvement of trauma care and optimize outcomes of such patients.

\section{Acknowledgements}

The authors thank Ministry of Health, Community Development, Gender, Elderly and Children, and staff at the regional and district hospitals in Tanzania.

\section{Funding}

This was a non-funded project; the principal investigators used their own funds to support the data collection and logistics.

\section{Availability of data and materials}

The datasets used and/or analyzed during the current study are presented as additional supporting files in this manuscript.

\section{Authors' contributions}

HRS contributed to the conception and design of the study, acquired, analysed and interpreted the data, and drafted and revised the manuscript. JAM contributed to the design of the study, data acquisition and entry and also revised the manuscript. KM contributed to the design of the study, data acquisition and entry and also revised the manuscript. PMK contributed to the design of the study, data acquisition and entry and also revised the manuscript. SK contributed to the design of the study, data acquisition and entry and also revised the manuscript. VM contributed to the conception and assisted in the initial design of the study and critically revised the manuscript. MSR contributed to the conception and assisted in the initial design of the study and critically revised the manuscript. LAW contributed to the conception and assisted in the initial design of the study, data interpretation and critically revised the manuscript. TAR contributed to the conception, design of the study, data interpretation and critically revised the manuscript. All authors read and approved the final manuscript.

\section{Ethics approval and consent to participate}

The study protocol was reviewed and approved by the Institutional Review Board of the Muhimbili University of Health and Allied Sciences (MUHAS) and The Ministry of Health and social Welfare of Tanzania issued a permission to survey all of the hospitals (Ref.No.HB.209/450/01A/135). As no patient or provider identifying details were kept, and no patient contact was made, no patient consent was required.

\section{Consent for publication}

Not applicable.

\section{Competing interests}

The authors declare no conflicts of interest.

\section{Publisher's Note}

Springer Nature remains neutral with regard to jurisdictional claims in published maps and institutional affiliations.

\section{Author details}

${ }^{1}$ Department of Emergency Medicine, Muhimbili University of Health and Allied Sciences, P.O. Box 65001, Dar es Salaam, Tanzania. '2Department of Emergency Medicine, Muhimbili National Hospital, Dar es Salaam, Tanzania. ${ }^{3}$ Emergency Medicine Department, Al-Zahra Hospital Sharjan, Sharjan, United Arab Emirates. ${ }^{4}$ Department of Emergency Medicine, Carolinas Medical Center, Charlotte, NC, USA. ${ }^{5}$ Division of Emergency Medicine, University of Cape Town, Cape Town, South Africa. ${ }^{6}$ Emergency and Trauma Care Program, WHO, Geneva, Switzerland.

Received: 28 April 2017 Accepted: 8 October 2017 Published online: 13 October 2017

\section{References}

1. WHO | World report on child injury prevention [Internet]. WHO. [cited 2013 Nov 24]. Available from: http://www.who.int/violence_injury_prevention/ child/injury/world_report/en/

2. Dandona R, Kumar GA, Ameer MA, Ahmed GM, Dandona L. Incidence and burden of road traffic injuries in urban India. Inj Prev. 2008 Dec;14(6):354-9.

3. Mohan D. International journal of epidemiology. Int J Epidemiol. 2002;1:527-32.

4. Lopes MR, Oliveira MA, Pereira VOS, Lemos IPB, Auler JOC Jr, Michard F. Goal-directed fluid management based on pulse pressure variation monitoring during high-risk surgery: a pilot randomized controlled trial. Crit Care. 2007;11(5):R100.

5. Lopez AD, Mathers CD, Ezzati M, Jamison DT, Murray CJL. Measuring the Global Burden of Disease and Risk Factors, 1990-2001. In: Lopez AD, Mathers CD, Ezzati M, Jamison DT, Murray CJ, editors. Global Burden of Disease and Risk Factors [Internet]. Washington (DC): World Bank; 2006 [cited 2013 Nov 24]. Available from: http://www.ncbi.nlm.nih.gov/books/NBK11817/

6. Mathers CD, Loncar D. Projections of global mortality and burden of disease from 2002 to 2030. PLoS Med. 2006 Nov 28;3(11):e442.

7. Chekijian S, Paul M, Kohl VP, Walker DM, Tomassoni AJ, Cone DC, et al. The Global Burden of Road Injury: Its Relevance to the Emergency Physician. Emerg Med Int [Internet]. 2014 [cited 2017 Mar 19];2014. Available from: http://www.ncbi.n/m.nih.gov/pmc/articles/PMC3956281/

8. WHO | Road traffic injuries [Internet]. WHO. [cited 2016 Nov 26]. Available from: http://www.who.int/violence_injury_prevention/road_traffic/en/

9. Grivna M, Barss P, Stanculescu C, Eid HO, Abu-Zidan FM. Child and youth traffic-related injuries: use of a trauma registry to identify priorities for prevention in the United Arab Emirates. Traffic Inj Prev. 2013;14(3):274-82.

10. Odero W, Garner P, Zwi A. Road traffic injuries in developing countries: a comprehensive review of epidemiological studies. Tropical Med Int Health. 1997 May;2(5):445-60.

11. $\mathrm{WHO}$ | Injuries and violence: the facts [Internet]. WHO. [cited 2017 Jul 26]. Available from: http://www.who.int/violence_injury_prevention/key_facts/en/ 
12. WHO | The global burden of disease: 2004 update [Internet]. WHO. [cited 2013 Nov 24]. Available from: http://www.who.int/healthinfo/global_ burden_disease/2004_report_update/en/

13. Krug EG, Sharma GK, Lozano R. The global burden of injuries. Am J Public Health. 2000 Apr;90(4):523-6.

14. Christie N, Cairns S, Towner E, Ward H. How exposure information can enhance our understanding of child traffic "death leagues.". Inj Prev. 2007 Apr;13(2):125-9.

15. World Bank. World bank data [Internet]. World bank data 2017. Available from: http://data.worldbank.org/country/tanzania

16. Reynolds TA, Mfinanga JA, Sawe HR, Runyon MS, Mwafongo V. Emergency care capacity in Africa: a clinical and educational initiative in Tanzania. J Public Health Policy. 2012 Dec;33(S1):S126-37.

17. Nicks BA, Sawe HR, Juma AM, Reynolds TA. The state of emergency medicine in the United Republic of Tanzania. African Journal of Emergency Medicine. 2012 Sep;2(3):97-102.

18. Moshiro C, Heuch I, Åstrøm AN, Setel P, Hemed Y, Kvåle G. Injury morbidity in an urban and a rural area in Tanzania: an epidemiological survey. BMC Public Health. 2005 Jan 28;5(1):11.

19. Boniface R, Museru L, Kiloloma O, Munthali V. Factors associated with road traffic injuries in Tanzania. Pan Afr Med J [Internet]. 2016 Feb 19 [cited 2016 Dec 14];23. Available from: http:/wwww.ncbinlm.nih.gov/pmc/articles/PMC4862800/

20. Chalya PL, Mabula JB. Dass RM, Mbelenge N, Ngayomela IH, Chandika AB, et al. injury characteristics and outcome of road traffic crash victims at Bugando medical Centre in northwestern Tanzania. J Trauma Manag Outcomes. 2012 Feb 9;6:1.

21. Ml M, Mc N, Mt L. Road Traffic Accidents in Tanzania: A Ten Year Epidemiological Appraisal. East and Central African Journal of Surgery. 7(1):23-6.

22. Casey ER, Muro F, Thielman NM, Maya E, Ossmann EW, Hocker MB, et al. Analysis of traumatic injuries presenting to a referral hospital emergency Department in Moshi, Tanzania. Int J Emerg Med. 2012 Jun 8:5(1):28.

23. Tanzania TBST. | demographic and health survey 2010. Tanzania bureau of Statistics. 2010;

24. Kuzma K, Lim AG, Kepha B, Nalitolela NE, Reynolds TA. The Tanzanian trauma patients' prehospital experience: a qualitative interview-based study. BMJ Open. 2015 Apr 1;5(4):e006921.

25. Mukhopadhyay B, Boniface R, Razek T. TRAUMA IN TANZANIA: Researching Injury in a low-Resource Setting. Mcgill J Med [Internet]. 2009 Nov 16 [cited 2013 Oct 1];12(2). Available from: http://www.ncbi.nlm.nih.gov/pmc/articles/ PMC2997249/

26. Boniface R, Museru L, Kiloloma O, Munthali V. Factors associated with road traffic injuries in Tanzania. Pan African Medical Journal [Internet]. 2016 Feb 19 [cited 2016 Dec 26];23(46). Available from: http://www.panafrican-medjournal.com/content/article/23/46/full/\#.WGDK5ry1Ldk

27. Seidenberg P, Cerwensky K, Brown RO, Hammond E, Mofu Y, Lungu J, et al. Epidemiology of injuries, outcomes, and hospital resource utilisation at a tertiary teaching hospital in Lusaka, Zambia. African Journal of Emergency Medicine. 2014 Sep 1;4(3):115-22.

28. MOI. Muhimbili Orthopaedic Institute (MOI). The Muhimbili Orthopaedic Institute (MOl).

29. Bardosh K, Sambo M, Sikana L, Hampson K, Welburn SC. Eliminating rabies in Tanzania? Local understandings and responses to mass dog vaccination in Kilombero and Ulanga districts. PLoS Negl Trop Dis. 2014 Jun;8(6):e2935.

30. Bayreuther J, Wagener S, Woodford M, Edwards A, Lecky F, Bouamra O, et al. Paediatric trauma: injury pattern and mortality in the UK. Arch Dis Child Educ Pract Ed. 2009 Apr;94(2):37-41.

31. Kehoe A, Smith JE, Edwards A, Yates D, Lecky F. The changing face of major trauma in the UK. Emerg Med J. 2015 Dec;32(12):911-5.

32. Outwater AH, Ismail H, Mgalilwa L, Justin Temu M, Mbembati NA. Burns in Tanzania: morbidity and mortality, causes and risk factors: a review. Int J Burns Trauma. 2013 Jan 24;3(1):18-29.

33. Mishra B. Sinha (Mishra) ND, Sukhla S, Sinha a. Epidemiological study of road traffic accident cases from western Nepal. Indian I Community Med. 2010 Jan;35(1):115-21.

34. Patel A, Krebs E, Andrade L, Rulisa S, Vissoci JRN, Staton CA. The epidemiology of road traffic injury hotspots in Kigali, Rwanda from police data. BMC Public Health. 2016 Aug 2;16:697.

35. Huang H, Yin Q, Schwebel DC, Li L, Examining Road HG. Traffic mortality status in China: a simulation study. PLoS One. 2016 Apr 12;11(4):e0153251.

36. Mcllvenny S. Road traffic accidents - a challenging epidemic. Sultan Qaboos Univ Med J. 2006 Jun;6(1):3-5.

\section{Submit your next manuscript to BioMed Central and we will help you at every step:}

- We accept pre-submission inquiries

- Our selector tool helps you to find the most relevant journal

- We provide round the clock customer support

- Convenient online submission

- Thorough peer review

- Inclusion in PubMed and all major indexing services

- Maximum visibility for your research

Submit your manuscript at www.biomedcentral.com/submit
C Biomed Central 